\title{
PENGENDALIAN PERSEDIAAN BAHAN BAKU TEBU DI PG X
}

\author{
Nila Kandi1), dan Hendrik Johannes Nadapdap2) \\ 1,2)Universitas Kristen Satya Wacana Salatiga, Jl. Diponegoro 52-60 Salatiga-Indonesia \\ 1)e-mail: nkandi240@gmail.com
}

(Diterima 20 Mei 2020 / Disetujui 23 Juni 2020)

\begin{abstract}
Sugarcane is one of the plantation crops which is used as raw material for making sugar. The efficiency of inventory is very important for a sugar factory. The purpose of this study is to determine the order level, order frequency, the amount of safety stock (Safety Stock), re-order points (sugarcane raw material) which is economical and to know the total inventory cost (Total Inventory Cost) of sugarcane raw material economical in PG X. The method of determining the area of this research was carried out intentionally (purposive). The research method uses the descriptive-analytic method. The analytical tool used is Economic Order Quantity (EOQ), Re-Order Points (ROP), Safety Stock (SS), and Total Inventory Cost (TIC). The results of the 2018 and 2019 EOQ calculations show it is not yet economical. The 2018 EOQ calculation was 1.688,79 tons greater than the number of orders made by PG X by 1.483,9 tons and the 2019 EOQ calculation was 3.074 tons greater than the number of bookings made by $P G X$ by 976,6 tons. The value of the safety stock in 2018 amounted to 1.483,9 tons and in 2019 it was 976,6 tons. The value of ROP in the supply of raw sugar cane in 2018 was 2.967,8 tons and in 2019 it was 1.953,2 tons. The 2018 TIC value is Rp. 139.031.870 smaller than the cost of inventory incurred by the company of Rp. 158.302 .102 and the 2019 TIC value of Rp. 208.014.632 less than the cost of inventory incurred by the company of Rp. 654.250.185. The results of the last two years calculations indicate the inefficiency of orders made because it causes the frequency of orders is greater and the inventory costs incurred by PG X are higher., so with economic calculations, the order frequency will be less and the total cost of inventory will be lower.
\end{abstract}

Keywords: EOQ, ROP, Sugarcane, SS, and TIC

\begin{abstract}
ABSTRAK
Tebu merupakan salah satu tanaman perkebunan yang dijadikan sebagai bahan baku pembuatan gula. Efisiensi persediaan bahan baku tebu sangat penting bagi sebuah pabrik gula. Tujuan penelitian ini mengetahui tingkat pemesanan, frekuensi pemesanan, jumlah persediaan pengaman (Safety Stock), titik pemesanan ulang (Re-Order Point) dengan jumlah yang ekonomis dan mengetahui total biaya persediaan (Total Inventory Cost) bahan baku tebu yang ekonomis di PG X. Metode dalam penentuan daerah penelitian ini dilakukan secara sengaja (purposive). Penelitian ini menggunakan metode deskriptif analitik. Alat analisis yang digunakan adalah Economic Order Quantity (EOQ), Re-Order Point (ROP), Safety Stock (SS), dan Total Inventory Cost (TIC). Hasil perhitungan EOQ tahun 2018 dan 2019 menunjukkan belum ekonomis. Perhitungan EOQ tahun 2018 sebesar 1.688,79 ton lebih besar dari jumlah pemesanan perhitungan PG X yaitu sebesar 1.483,9 ton dan perhitungan EOQ tahun 2019 sebesar 3.074 ton lebih besar dari jumlah pemesanan yang dilakukan oleh PG X sebesar 976,6 ton. Nilai stok pengaman (Safety Stock) sebesar tahun 2018 sebesar 1.483,9 ton dan tahun 2019 sebesar 976,6 ton. Nilai ROP dalam pengadaan bahan baku tebu tahun 2018 sebesar 2.967,8 ton dan tahun 2019 sebesar 1.953,2 ton. Nilai TIC tahun 2018 sebesar Rp. 139.031 .870 lebih kecil dari biaya persediaan perhitungan perusahaan yaitu sebesar Rp. 158.302 .102 dan nilai TIC tahun 2019 sebesar Rp. 208.014.632 lebih kecil dari biaya persediaan perhitungan perusahaan yaitu sebesar Rp. 654.250.185. Hasil perhitungan dua tahun terakhir ini menunjukkan adanya inefisiensi pemesanan karena menyebabkan frekuensi pemesanan semakin besar dan biaya persediaan PG X semakin tinggi, sehingga dengan perhitungan ekonomis dapat mengurangi frekuensi pemesanan dan biaya total persediaan akan semakin rendah.
\end{abstract}

Kata kunci: EOQ, SS, ROP, TIC dan Tebu 


\section{PENDAHULUAN}

Manajemen merupakan suatu seni mengatur yang melibatkan proses, cara dan tindakan tertentu. Dalam hal ini manajemen yang dimaksud yaitu aktivitas perencanaan, pengorganisasian, pengarahan dan pengendalian atau pengawasan. Hal ini dilakukan untuk menentukan dan mencapai tujuan secara efisien dan efektif melalui orang lain (Sulastri, 2012).

Persediaan (inventory) adalah sumber daya ekonomi berbentuk fisik yang perannya sangat penting untuk diadakan dan dipelihara dalam menjamin kelancaran proses produksi. Persediaan yang dimaksud diantaranya bahan baku (raw material), komponen rakitan (component), barang yang sedang dalam proses pengerjaan (working in process inventory), produk jadi (finish product), dan bahan pembantu (substance material) (Haming \& Numajamuddin, 2014). Dalam kelancaran proses produksi di perusahaan, persediaan bahan baku mempunyai peran penting karena persediaan bahan baku mempunyai pengaruh yang sangat besar terhadap kelancaran dalam proses produksi. Persediaan merupakan bahan atau barang yang disimpan untuk memenuhi tujuan tertentu (Jan \& Tumewu, 2019).

Manajemen persediaan merupakan kegiatan yang dilakukan oleh perusahaan dalam pembuatan keputusan terkait kebutuhan akan bahan baku ataupun barang untuk keperluan kegiatan perusahaan baik produksi maupun penjualan dapat terpenuhi secara optimal dengan resiko yang seminimal mungkin. Persediaan yang berlebihan (over stock) menjadi pemborosan bagi perusahaan karena menyebabkan biaya selama penyimpanan meningkat. Selain itu persediaan yang terlalu besar akan menjadi barang modal yang menganggur dan tidak berputar. Sebaliknya jika kekurangan persediaan (out of stock) dapat mengganggu dalam kelancaran produksi, sehingga mengakibatkan berkurangnya pelayanan terhadap konsumen (Iqbal, Aprizal, \& Wali, 2017).

Economic Order Quantity (EOQ) adalah teknik dalam penentuan jumlah pemesanan yang dilakukan dengan menentukan berapa jumlah pemesanan yang ekonomis untuk setiap kali pesan dengan frekuensi yang telah dihitung, serta waktu dilakukan pemesanan ulang. Metode ini memiliki tujuan meminimalkan total biaya persediaan (Total Inventory Cost), sehingga dalam pengadaan persediaan menjadi efisien dan dapat jumlah unit yang dipesan optimal (Apriyani \& Muhsin, 2017). Sedangkan menurut Heizer \& Barry (2016) Economic Order Quantity juga merupakan teknik pengendalian persediaan yang paling sering digunakan dan relatif mudah digunakan.

Pentingnya manajemen persediaan bahan baku yang tepat tidak kekurangan ataupun kelebihan pada perusahaan yang berbahan baku primary product. Salah satu penyebab pentingnya diadakan persediaan bahan baku tebu ini karena bahan baku tersebut dipesan dalam jumlah yang besar. Sementara proses produksi berjalan kontinyu dan menuntut kualitas akhir produk yang tinggi. Selain itu dengan manajemen persediaan yang baik dapat mengurangi biaya yang dikeluarkan perusahaan (Heizer \& Barry, 2016).

Beberapa permasalahan dalam industri gula diantaranya pertumbuhan produksi gula cenderung menurun saat permintaan konsumsi gula meningkat, tingginya harga gula dan efisiensi pabrik gula yang rendah (Prasetyo, 2017). Dalam kegiatan produksinya, PG X memiliki kendala yaitu proses produksi mengalami under capacity dari kapasitas giling yang dimiliki. Hal tersebut dilihat dari jumlah bahan baku tebu yang digiling kurang dari kapasitas giling, sehingga frekuensi pemesanan yang dilakukan lebih banyak dan biaya pemesanan yang dikeluarkan lebih besar.

Salah satu kegiatan produksi yang dapat dijadikan sebagai alternatif untuk meminimalisasi permasalahan tersebut adalah dengan penentuan Economic Order Quantity bahan baku tebu yang dibutuhkan PG X. Dalam penelitian ini menggunakan metode analisis Economic Order Quantity (EOQ), Safety Stock (SS), Re-Order Point (ROP), dan Total Inventory Cost (TIC). Metode analisis EOQ digunakan untuk mengetahui jumlah atau kuantitas pemesanan ekonomis. Metode ini berfungsi membantu suatu perusahaan dalam pengambilan keputusan agar saat pengadaan bahan baku tidak berlebihan dan tidak terjadi kekurangan dengan jumlah yang optimal, sehingga didapatkan frekuensi pemesanan yang ekonomis yang dapat menghemat biaya (Hermawan, 2012). 
Penelitian ini bertujuan untuk mengetahui jumlah pemesanan, frekuensi pemesanan, jumlah persediaan pengaman (Safety Stock), titik pemesanan ulang (Re-Order Point) bahan baku tebu yang ekonomis dan mengetahui total biaya persediaan (Total Inventory Cost) bahan baku tebu yang ekonomis di PG X.

\section{METODE}

\section{LOKASI PENELITIAN}

Penelitian dilaksanakan di PG X. Penentuan lokasi penelitian dilakukan secara sengaja (purposive) dengan kriteria bahwa pabrik tersebut masih aktif memproduksi gula pasir. Waktu penelitian dilaksanakan pada bulan Januari 2020.

\section{METODE ANALISIS DATA}

Jenis penelitian menggunakan penelitian kuantitatif dengan metode deskriptif analitik. Unit analisis penelitian ini yaitu pengendalian terkait persediaan bahan baku tebu di PG X. Unit amatan penelitian ini adalah ketersediaan tebu, pasokan tebu, dan biaya persediaan tebu untuk produksi gula. Jenis data sekunder yang digunakan dalam penelitian ini yaitu data jumlah tebu digiling, biaya pemesanan, biaya penyimpanan dan biaya persediaan.

Permasalahan yang diangkat dalam penelitian ini adalah terjadinya under capacity giling yang disebabkan oleh keterlambatan bahan baku tebu, sehingga perlu dilakukan pengendalian pada pemesanan bahan baku tebu. Metode analisis yang digunakan yaitu analisis persediaan bahan baku berdasarkan metode Economic Order Quantity (EOQ), Safety Stock (SS), Re-Order Point (ROP), dan Total Inventory Cost (TIC).

1) Analisis Persediaan Bahan Baku Berdasarkan Metode EOQ

Metode EOQ digunakan untuk mengetahui jumlah pemesanan ekonomis. Metode ini berfungsi membantu suatu perusahaan dalam pengambilan keputusan agar saat pengadaan bahan baku tidak berlebihan dan tidak terjadi kekurangan dengan jumlah yang optimal (Yuliana \& Sudjana, 2016).

$$
\mathrm{Q}^{*}=\sqrt{\frac{2 D S}{H}}
$$

Keterangan :

$\mathrm{Q}^{*}$ : jumlah optimal unit per pesanan (EOQ)

D : perminrtaan tahunan dalam unit untuk barang persediaan

$\mathrm{S}$ : biaya pemasangan atau pemesanan untuk setiap pesanan

$\mathrm{H}$ : biaya penyimpanan atau membawa persediaan per unit per tahun (Heizer \& Barry, 2016).

2) Frekuensi Pemesanan

$$
\mathrm{I}=\frac{D}{E O Q}
$$

Keterangan :

I : frekuensi pemesanan optimal

EOQ : jumlah pemesanan ekonomis

D : jumlah penggunaan bahan baku dalam satu periode per unit (Rahmawati, Rahayu, \& Ani, 2018).

3) Persediaan Pengaman (Safety Stock)

$$
\mathrm{SS}=\mathrm{d} \times \mathrm{L}
$$

Keterangan :

SS : Safety Stock

d : permintaan harian

L : waktu tunggu pesanan atau jumlah hari kerja yang dibutuhkan untuk mengantarkan sebuah pesanan (Heizer \& Barry, 2016).

4) Titik Pemesanan Ulang (Re-Order Point)

$$
\mathrm{ROP}=(\mathrm{d} \times \mathrm{L})+\mathrm{SS}
$$

Keterangan :

ROP : Re-Order Point

d : permintaan harian

L : waktu tunggu pesanan atau jumlah hari kerja yang dibutuhkan untuk mengantarkan sebuah pesanan

SS : Safety Stock (Heizer \& Barry, 2016).

5) Biaya Persediaan (Total Inventory Cost)

$$
\text { TIC }=\left(\frac{D}{Q} \times S\right)+\left(\frac{Q}{2} \times H\right)
$$

Keterangan :

TIC : Total Inventory Cost

Q : jumlah optimal unit per pesanan (EOQ)

D : permintaan tahunan dalam unit untuk barang persediaan

S : biaya pemasangan atau pemesanan untuk setiap pesanan

$\mathrm{H}$ : biaya penyimpanan atau membawa 


\section{PENGUMPULAN DATA}

Teknik pengumpulan data dilakukan dengan observasi, wawancara, dan dokumentasi. Observasi dilakukan untuk memperoleh informasi terkait proses pemesanan dan penyimpanan bahan baku tebu. Wawancara dilakukan untuk memperoleh informasi persentase sisa pagi yang ditetapkan PG X dan besarnya kapasitas giling pabrik. Dokumentasi dilakukan untuk memperoleh data pemesanan bahan baku tebu selama 5 tahun terakhir, data biaya pemesanan tahun 2018-2019, dan biaya penyimpanan tahun 20182019.

Saat ini keadaan PG X belum melakukan pemesanan bahan baku secara ekonomis, sehingga dapat merugikan dan menghambat jalannya produksi jika bahan baku tidak tersedia dengan cukup. Dengan dilakukan penerapan metode analisis EOQ di PG X ini, maka dapat diketahui jumlah persediaan bahan baku yang ekonomis saat PG melakukan proses produksinya. Penentuan jumlah persediaan bahan baku yang tepat dan ekonomis dapat menghemat biaya persediaan. Dengan adanya metode analisis EOQ seperti diatas, maka PG X dapat memperkirakan jumlah pemesanan bahan baku yang dipesan secara ekonomis, sehingga produksi gula pasir dapat maksimal. Berdasarkan uraian diatas kerangka pemikiran pada penelitian ini, ditampilkan pada gambar 1 .

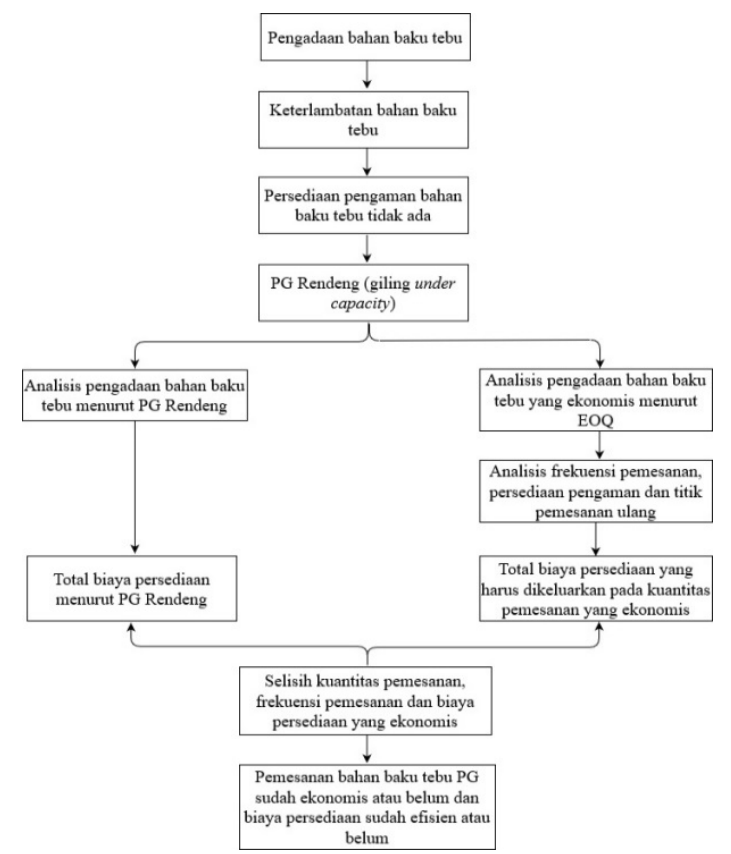

Gambar 1. Kerangka Pemikiran Penelitian

\section{HASIL DAN PEMBAHASAN}

\section{PERSEDIAAN BAHAN BAKU TEBU DI PG X}

Pasokan bahan baku tebu di PG X setiap musim giling atau setiap tahun jumlahnya berbeda-beda. Perbedaan jumlah pasokan tebu ini dipengaruhi oleh jumlah petani tebu rakyat yang setiap tahunnya tidak tetap. Selain itu dipengaruhi juga oleh loyalitas petani untuk tetap memasok hasil tebunya pada PG X .

Tabel 1. Jumlah Tebu Digiling dan Lama Hari Giling PG X Tahun 2015-2019

\begin{tabular}{ccccr}
\hline Tahun & $\begin{array}{c}\text { Tebu } \\
\text { Sendiri } \\
\text { (Ton) }\end{array}$ & $\begin{array}{c}\text { Tebu } \\
\text { Rakyat } \\
\text { (Ton) }\end{array}$ & $\begin{array}{c}\text { Total } \\
\text { Tebu } \\
\text { Giling } \\
\text { (Ton) }\end{array}$ & $\begin{array}{c}\text { Hari } \\
\text { Giling }\end{array}$ \\
\hline 2015 & 312,2 & $195.340,7$ & 195.653 & 92 \\
2016 & 424,9 & $156.886,9$ & 157.312 & 112 \\
2017 & $21.864,1$ & $128.901,8$ & 150.766 & 97 \\
2018 & $26.890,3$ & $115.564,4$ & 142.455 & 96 \\
2019 & $52.031,7$ & $30.978,9$ & 83.011 & 85 \\
\hline Sumbr: Quality
\end{tabular}

Berdasarkan data tabel 1 dapat diketahui bahwa selama lima tahun terakhir jumlah tebu yang digiling mengalami penurunan. Selama lima tahun terakhir pasokan tebu dari Tebu Rakyat (TR) lebih banyak dibandingkan Tebu Sendiri (TS). Namun tahun 2019 pasokan bahan baku dari TS lebih banyak dibandingkan dari TR. Pada tahun 2019 jumlah TS sebesar 52.031,7 ton dengan persentase $63 \%$ sedangkan jumlah TR sebesar $30.978,9$ ton dengan persentase $37 \%$. Pada tahun 2019 jumlah tebu yang digiling juga mengalami penurunan yang besar. Hal ini dikarenakan adanya revitalisasi pabrik sehingga terjadi pemberhentian giling yang menyebabkan pasokan bahan baku tebu mengalami penurunan.

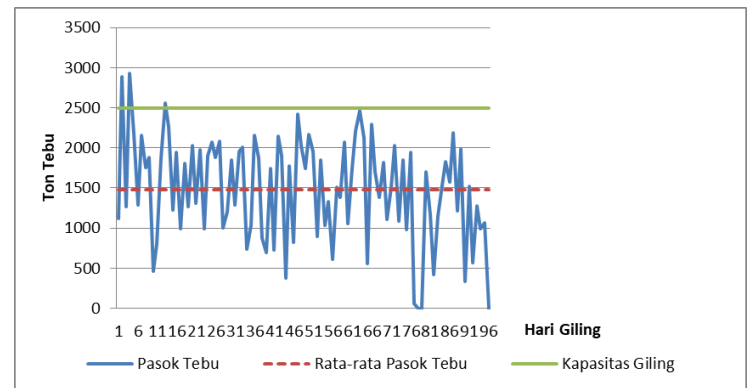

Gambar 2. Grafik Data Pasokan Tebu Harian PG X Tahun 2018 
Berdasarkan grafik pada gambar 2 diketahui bahwa rata-rata pasokan bahan baku tebu PG X tahun 2018 sebesar 1.483,9 ton per hari giling. Selain itu diketahui juga kapasitas giling yang dimiliki sebesar 2500 TCD (Ton Cane per Day). Selisih antara rata-rata pasokan bahan baku tebu dengan kapasitas giling sebesar 1.016,1 ton per hari. Hal ini menunjukkan bahwa secara kuantitas ketersediaan bahan baku tebu di PG X masih kurang.

Kemampuan giling setiap PG X berbedabeda tiap hari gilingnya. Bahan baku tebu yang dapat digiling setiap harinya mengalami ketidakstabilan kapasitas giling. Ketidakstabilan ini terjadi karena keterlambatan bahan baku tebu yang datang dan adanya kerusakan pada pabrik, sehingga mengakibatkan adanya kesenjangan antara pasokan bahan baku tebu dengan kuantitas yang digiling, sehingga menyebabkan adanya sisa pagi bahan baku tebu. Sisa pagi merupakan sisa persediaan tebu untuk hari giling berikutnya yang didapatkan dari selisih antara tebu yang masuk dengan tebu yang digiling per hari. Sisa pagi ini menyebabkan bahan baku tebu harus menginap di pabrik sehingga kualitasnya menurun.

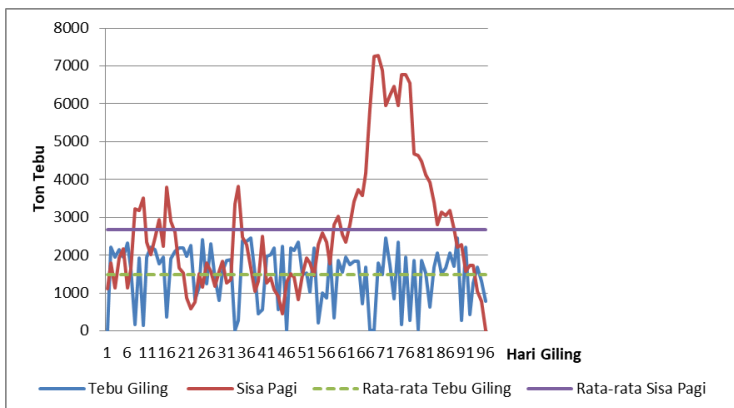

\section{Gambar 3. Grafik Data Giling dan Sisa Pagi} Tebu PG X Tahun 2018

Berdasarkan pada grafik gambar 3 dapat diketahui bahwa rata-rata tebu yang digiling yaitu sebesar $1.483,9$ ton per hari dan rata-rata sisa pagi sebesar 2.675 ton per hari. Selisih rata-rata tebu yang digiling dengan kapasitas maksimal giling yang dimiliki pabrik yaitu sebesar 1.016,4 ton atau $40,6 \%$. Salah satu penyebab hal ini terjadi karena keterlambatan pasokan tebu. Selain itu juga disebabkan oleh giling yang dimulai siang hari dan terjadi kerusakan pabrik pada saat giling yang menyebabkan terjadi pemberhentian giling sementara sehingga terdapat sisa tebu pada hari tersebut. Kondisi tersebut mengakibatkan jumlah tebu yang digiling per hari tidak memenuhi kapasitas giling yang ada. Kapasitas yang dimiliki PG X sebesar 2.500 TCD. Rata-rata sisa pagi di PG $\mathrm{X}$ juga melebihi dengan batas yang sudah ditetapkan. Batas jumlah sisa pagi yang ditetapkan PG X sebesar 30\% dari kapasitas giling yaitu sebesar 750 ton.

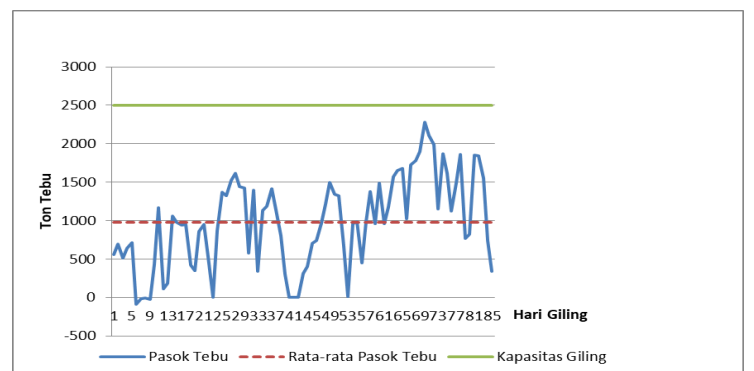

\section{Gambar 4. Grafik Data Pasokan Tebu Harian PG X Tahun 2019}

Berdasarkan pada grafik gambar 4 dapat diketahui bahwa rata-rata pasokan bahan baku tebu PG X tahun 2019 yaitu sebesar 976,6 ton per hari giling. Selisih antara rata-rata pasokan tebu dengan kapasitas giling sebesar 1.525,05 ton per hari. Hal ini menunjukkan bahwa secara kuantitas ketersediaan bahan baku tebu di PG X masih kurang.

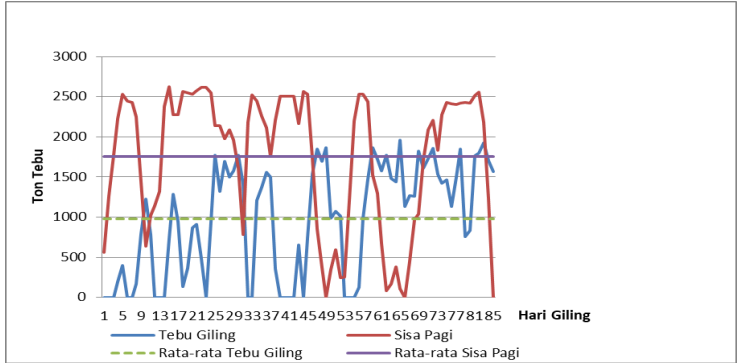

\section{Gambar 5. Grafik Data Giling dan Sisa Pagi Tebu PG X Tahun 2019}

Berdasarkan pada grafik gambar 5 dapat diketahui bahwa rata-rata tebu yang digiling yaitu sebesar 976,6 ton per hari dan rata-rata sisa pagi yaitu sebesar 1.755 ton per hari. Rata-rata tebu yang digiling setiap harinya sangat jauh dari kapasitas maksimal giling yang dimiliki pabrik. Kapasitas yang dimiliki PG X sebesar 2.500 TCD. Selisih rata-rata giling dengan kapasitas giling milik pabrik yaitu sebesar $1.523,4$ ton per hari atau 61\%. Rata-rata sisa pagi di PG X juga melebihi 
dengan batas yang sudah ditetapkan. Batas jumlah sisa pagi yang ditetapkan PG X adalah sebesar $30 \%$ dari kapasitas giling yaitu sebesar 750 ton

\section{PEMESANAN BAHAN BAKU TEBU}

Pemesanan bahan baku tebu yang ekonomis dapat diketahui dengan perhitungan Economic Order Quantity (EOQ). Selain memperhitungkan jumlah pemesanan tebu, dilakukan juga perhitungan biaya pemesanannya. Biaya pemesanan didapatkan dari jumlah premi, biaya tebang dan biaya angkut. Biaya penyimpanan bahan baku tebu dihitung dari persentase penurunan atau penyusutan tebu selama menunggu proses giling dikali dengan harga gula per unit (kg).

Pada tabel 2 dan tabel 3 menjelaskan mengenai rincian biaya pemesanan yang dilakukan PG X pada tahun 2018 dan 2019.

Tabel 2. Rincian Biaya Pemesanan PG X Tahun 2018

\begin{tabular}{lr}
\hline \multicolumn{1}{c}{ Uraian } & \multicolumn{1}{c}{ Biaya (Rp) } \\
\hline Upah Pokok & 66.384 .360 \\
Premi-Premi : & \\
Premi Bersih & 10.537 .200 \\
Upah Mandor & 10.537 .200 \\
Tebu Tidak di Kletek & 7.376 .040 \\
Tebu Roboh & 10.537 .200 \\
Antar Jemput & 5.268 .600 \\
Angkutan Tebu & 47.417 .400 \\
Total Biaya Pemesanan & 158.058 .000 \\
Total Biaya Pemesanan/Hari & $1.646 .437,5$ \\
\hline Sumber : Data Sekunder Bagian Quality Control, 2020
\end{tabular}

Tabel 3. Rincian Biaya Pemesanan PG X Tahun 2019

\begin{tabular}{lr}
\hline \multicolumn{1}{c}{ Uraian } & \multicolumn{1}{c}{ Biaya (Rp) } \\
\hline Upah Pokok & 318.112 .860 \\
Premi-Premi : & \\
Premi Bersih & 22.243 .800 \\
Upah Mandor & 40.783 .700 \\
Tebu Tidak di Kletek & 7.796 .560 \\
Tebu Roboh & 9.270 .930 \\
Antar Jemput & 22.337 .310 \\
Angkutan Tebu & 233.572 .990 \\
Total Biaya Pemesanan & 654.118 .150 \\
Total Biaya Pemesanan/Hari & $7.695 .507,65$ \\
\hline Sumber : Data Primer Diolah, 2020 &
\end{tabular}

Pada tabel 4 dibawah ini menjelaskan mengenai frekuensi dan selisih jumlah pemesanan bahan baku tebu yang dilakukan PG X dengan pemesanan berdasarkan EOQ.

Contoh perhitungan yang dilakukan dengan metode EOQ yaitu tahun 2018 dan tahun 2019.

Tabel 4. Frekuensi dan Selisih Jumlah Pemesanan Bahan Baku Tebu PG X dengan Pemesanan Berdasarkan EOQ

$\begin{array}{lll}\text { Tahun } & 2018 & 2019\end{array}$

\begin{tabular}{lrr}
\hline $\begin{array}{lr}\text { Frekuensi Pemesanan } \\
\text { Ekonomis (hari) }\end{array}$ & & \\
$\begin{array}{l}\text { Frekuensi Pemesanan } \\
\text { PG X (hari) }\end{array}$ & & \\
Jumlah Pemesanan EOQ & 96 & \\
(ton/hari) & $1.688,79$ & 3.074 \\
Perhitungan PG X & & \\
(ton/hari) & $1.483,9$ & 976,6 \\
Selisih (ton/hari) & 204,89 & $2.097,4$ \\
\hline
\end{tabular}
Sumber : Data Primer Diolah, 2020

Berdasarkan perhitungan EOQ atau jumlah pemesanan bahan baku tebu yang ekonomis pada tahun 2018 didapatkan hasil sebesar 1.688,79 ton. Hasil perhitungan EOQ didapatkan frekuensi pemesanan sebanyak 84 kali. Sedangkan pemesanan yang dilakukan PG lebih banyak yaitu 96 kali. Hal ini menunjukkan bahwa pemesanan bahan baku tebu di PG X belum ekonomis sesuai dengan pernyataan Andoyo dan Wibowo (2019) bahwa apabila bahan baku yang dipesan lebih sedikit maka frekuensi pemesanan semakin besar dan biaya persediaan bahan baku yang dikeluarkan PG X semakin besar. Pada tahun 2019 hasil EOQ sebesar 3.074 ton. Hasil perhitungan EOQ didapatkan frekuensi pemesanan sebanyak 27 kali. Sedangkan pemesanan yang dilakukan oleh PG lebih banyak yaitu 85 kali. Hasil perhitungan EOQ dan frekuensi pemesanan tahun 2018 dan 2019 jauh berbeda karena pada tahun 2019 PG X masih dalam proses revitalisasi pabrik untuk penambahan kapasitas giling, yang dimana pabrik mengalami pemberhentian sementara sehingga pemesanan bahan baku tebu per harinya dilakukan pembatasan. Pembatasan pemesanan ini menyebabkan pemesanan per harinya lebih sedikit sehingga mengakibatkan frekuensi pemesanan menjadi besar. Selain itu juga terjadi keterlam- 
batan bahan baku tebu dan hari giling yang ditetapkan juga lebih singkat.

\section{STOK PENGAMAN (SAFETY STOCK) DAN TITIK PEMESANAN ULANG (RE-ORDER POINT)}

Proses produksi dikatakan baik saat ke; lancaran faktor-faktor produksinya tidak terganggu. Salah satu faktor produksinya adalah bahan baku. Bahan baku yang diolah harus dijaga kelancaran pengadaannya agar proses produksi tidak terganggu atau terhenti. Dalam kegiatan produksinya perusahaan harus memiliki persediaan pengaman (Safety Stock) pada saat lead time sebagai pengaman lancarnya proses produksi sebelum melakukan pemesanan ulang bahan baku tebu.

Pemesanan ulang bahan baku tebu yang akan dilakukan untuk masa produksi selanjutnya disebut Titik Pemesanan Ulang (Re-Order Point). Dalam pemesanan ulang tebu harus mengetahui besarnya persediaan pengaman (safety stock) dan penggunaan bahan baku tebu selama waktu tunggu (lead time). PG X tidak memiliki stok pengaman seperti perusahaan pada umumnya. Hal ini dikarenakan tebu memiliki sifat yang mudah rusak jika disimpan dalam waktu yang lama dan harus dalam keadaan segar saat digiling atau digiling <36 jam sesuai standar yang ditentukan. Standar yang ditentukan PG X berpengaruh pada lead time bahan baku tebu. Lead time bahan baku tebu maksimal selama 1 hari. Berdasarkan perhitungan yang dilakukan, safety stock yang sebaiknya diterapkan pada PG X tahun 2018 sebanyak 1483,9 ton dan tahun 2019 sebanyak 976,6 ton.

Perhitungan titik pemesanan ulang dihitung dari kebutuhan bahan baku tebu per hari di PG X dikali dengan waktu tunggu dan ditambah dengan safety stock. Hasil perhitungan Re-Order Point tahun 2018 sebesar 2.967,8 ton dan tahun 2019 sebesar 1.953,2 ton. Hal ini menunjukkan bahwa ketika stok bahan baku tebu untuk pabrik sebesar nilai ROP atau lebih kecil maka PG X harus melakukan pemesanan ulang.

\section{BIAYA PERSEDIAAN BAHAN BAKU TEBU}

Dalam proses pengolahan gula pasir, terdapat beberapa komponen biaya yang harus dikeluarkan oleh PG terkait pengadaan bahan baku tebu. Biaya yang dikeluarkan diantaranya biaya pemesanan dan biaya penyimpanan. Rincian biaya persediaan tahun 2018 dan tahun 2019 dijelaskan pada tabel 5 dan tabel 6 berikut ini:

Tabel 5.Biaya Persediaan Berdasarkan Perhitungan Perusahaan Tahun 2018

\begin{tabular}{lrr}
\hline \multicolumn{1}{c}{$\begin{array}{c}\text { Komponen } \\
\text { Biaya }\end{array}$} & Biaya (Rp) & $\begin{array}{l}\text { Biaya/Hari } \\
\text { giling (Rp) }\end{array}$ \\
\hline $\begin{array}{l}\text { Biaya Pemesanan } \\
\text { Biaya }\end{array}$ & 158.058 .000 & $2.431 .661,5$ \\
$\begin{array}{l}\text { Penyimpanan } \\
\text { Total Biaya }\end{array}$ & $244.101,55$ & 164,5 \\
Persediaan & $158.302 .101,6$ & - \\
\hline
\end{tabular}

Data Primer Diolah, 2020

Tabel 6. Biaya Persediaan Berdasarkan Perhitungan Perusahaan Tahun 2019

\begin{tabular}{ccc}
\hline $\begin{array}{c}\text { Komponen } \\
\text { Biaya }\end{array}$ & Biaya (Rp) & $\begin{array}{l}\text { Biaya/Hari } \\
\text { giling (Rp) }\end{array}$ \\
\hline
\end{tabular}

\begin{tabular}{|c|c|c|}
\hline Biaya & & \\
\hline Pemesanan & & \\
\hline Bahan Baku & & \\
\hline Tebu & 654.118 .150 & $13.465 .217,05$ \\
\hline Biaya & & \\
\hline Penyimpan & & \\
\hline Bahan Baku & & \\
\hline Tebu & $132.034,97$ & 135,2 \\
\hline Total Biaya & & \\
\hline Persediaan & 654.250 .185 & \\
\hline
\end{tabular}

Pada tabel 7 dibawah ini menjelaskan mengenai biaya persediaan bahan baku tebu di PG X tahun 2018 dan tahun 2019.

Tabel 7. Biaya Persediaan Bahan Baku Tebu di PG X Tahun 2018-2019 Jumlah Biaya Jumlah Biaya

Tahun Persediaan PG X Persediaan (Rp) Ekonomis (Rp)

\begin{tabular}{lll}
2018 & 158.302 .102 & 139.031 .870 \\
2019 & 654.250 .185 & 208.014 .632 \\
\hline \multicolumn{2}{l}{ Sumber : Data Primer Diolah, 2020 }
\end{tabular}

Berdasarkan hasil perhitungan pada tabel 7, diketahui bahwa metode EOQ dapat meminimalkan biaya pengadaan bahan baku tebu yang dikeluarkan PG X karena terdapat selisih sangat besar diantara dua perhitungan tersebut. Hal 
tersebut menunjukkan bahwa biaya persediaan di PG X lebih besar dibandingkan biaya persediaan yang dilakukan menurut perhitungan EOQ. Pada tahun 2018, biaya persediaan yang dikeluarkan PG X yaitu Rp. 158.302.102. Sedangkan dalam perhitungan EOQ, biaya persediaan yang seharusnya dikeluarkan yaitu sebesar Rp.139.031.870. Pada tahun 2019 biaya persediaan yang sudah dikeluarkan oleh PG X sebesar Rp. 654.250.185. Sedangkan biaya persediaan yang seharusnya dikeluarkan oleh PG X menurut hasil perhitungan EOQ sebesar Rp. 208.014.632. Selisih yang didapatkan sebesar Rp. 446.235.553. Nilai total biaya persediaan bahan baku tebu yang seharusnya dikeluarkan oleh PG X jauh berbeda dengan nilai total biaya persediaan menurut perhitungan EOQ. Hal ini menunjukkan apabila PG $\mathrm{X}$ menggunakan perhitungan Economic Order Quantity (EOQ) maka PG X dapat menghemat biaya dalam pemenuhan persediaan bahan baku tebu.

\section{SIMPULAN DAN SARAN}

\section{SIMPULAN}

1. Jumlah persediaan bahan baku tebu di PG X tahun 2018 dan 2019 belum ekonomis. Hasil perhitungan analisis EOQ tahun 2018 sebesar $1.688,79$ ton. Hasil perhitungan ini lebih besar dibandingkan dengan jumlah pemesanan di PG $\mathrm{X}$ yaitu sebesar $1.483,9$ ton. Hasil perhitungan EOQ menunjukkan adanya inefisiensi pemesanan pada PG X yang ditunjukkan dengan frekuensi pemesanan yang bertambah besar dan biaya persediaan yang meningkat. Stok pengaman (Safety Stock) sebesar tahun 2018 sebesar 1.483,9 ton/hari dan tahun 2019 sebesar 976,6 ton/hari. Nilai ROP dalam pengadaan bahan baku tebu tahun 2018 sebesar 2.967,8 ton dan tahun 2019 sebesar $1.953,2$ ton.

2. Nilai biaya total persediaan (TIC) pada tahun 2018 dan 2019 belum efisien. Hasil perhitungan TIC tahun 2018 sebesar Rp. 139.031.870. Hasil perhitungan ini lebih kecil dibandingkan dengan biaya persediaan pada PG X yaitu sebesar Rp. 158.302.102. Pada tahun 2019 nilai TIC sebesar Rp. 208.014.632. Hasil ini lebih kecil dibandingkan dengan biaya persediaan pada PG X yaitu sebesar Rp.
654.250.185. Hasil perhitungan TIC menunjukkan adanya inefisiensi biaya persediaan pada PG X. Dengan demikian perhitungan secara ekonomis dapat digunakan agar frekuensi pemesanan tebu semakin kecil, sehingga dapat mengurangi dan menghemat biaya persediaan dengan menyesuaikan kapasitas giling yang terpasang.

\section{SARAN}

1. Pengadaan dan frekuensi pemesanan bahan baku yang dilakukan PG disarankan sesuai dengan metode EOQ dengan menyesuaikan kapasitas giling yang dimiliki agar produksi gula lebih optimal dan biaya persediaan bahan baku yang dikeluarkan efisien.

2. Bagi penelitian selanjutnya yang meneliti di PG $\mathrm{X}$ penulis menyarankan dilakukan penelitian terkait penurunan atau penyusutan tebu saat waktu tunggu sebelum tebu digiling, sehingga biaya penyimpanan bahan baku tebu bisa diperhitungkan dengan pasti.

\section{DAFTAR PUSTAKA}

Apriyani, N., \& Muhsin, A. (2017). Analisis Pengendalian Persediaan Bahan Baku Dengan Metode Economic Order Quantity Dan Kanban Pada Pt Adyawinsa Stamping $\begin{array}{lll}\text { Industries. } & \text { Opsi, 10(2), }\end{array}$ https://doi.org/10.31315/opsi.v10i2.2108

Haming, M., \& Numajamuddin, M. (2014). Manajemen Produksi Modern Operasi Manufaktur dan Jasa Buku 2 (2nd ed.; A. Novianty, ed.). Jakarta: PT Bumi Aksara.

Heizer, J., \& Barry, R. (2016). Manajemen Operasi : Manajemen Keberlangsungan dan rantai pasokan. Jakarta: Salemba Empat.

Hermawan, I. (2012). Analisis penggunaan luas lahan tebu dan padi terkait dengan pencapaian swasembada gula di indonesia. Jurnal Ekonomi Dan Kebijakan Publik, 3(1), 47-63.

Iqbal, T., Aprizal, D., \& Wali, M. (2017). Aplikasi Manajemen Persediaan Barang Berbasis Economic Order Quantity (EOQ). Jurnal JTIK (Jurnal Teknologi Informasi Dan Komunikasi), 1(1),

48. 
Jan, A. H., \& Tumewu, F. (2019). Analisis economic order quantity (eoq) pengendalian persediaan bahan baku kopi pada pt . fortuna inti alam. Jurnal EMBA, 7(1).

Prasetyo, B. D. (2017). Menuju Industri Gula Yang Berdaya Saing. Seminar Nasional Agribisnis, 6. Indonesia: Universitas Galuh Ciamis.

Rahmawati, R., Rahayu, E. S., \& Ani, S. W. (2018). Analisis Penerapan Economic Order Quantity (Eoq) Di Pabrik Gula Madukismo Bantul. Caraka Tani: Journal of Sustainable Agriculture, $32(2), \quad 126$. https://doi.org/10.20961/carakatani.v32i2. 15120

Sulastri, L. (2012). Manajemen. Bandung: La Good's.

Yuliana, C., \& Sudjana, N. (2016). Penerapan model eoq (economic order quantity) dalam rangka meminimumkan biaya persediaan bahan baku (studi pada UD. Sumber Rejo Kandangan-Kediri). Jurnal Administrasi Bisnis S1 Universitas Brawijaya, 36(1), 1-9. 